\title{
THE AORTA AND PULMONARY ARTERIES IN FALLOT'S TETRALOGY
}

\author{
BY \\ J. NORMAN PATTINSON* AND RICHARD W. EMANUEL \\ From the Departments of Radiodiagnosis and Cardiology, Middlesex Hospital \\ Received February 22, 1956
}

Until the last decade our knowledge of the anatomy in Fallot's tetralogy had been derived from clinical observations, radiology, and post-mortem specimens. The advent of cardiac catheterization and particularly angiocardiography gave additional methods of studying this condition during life. Our observations are based on angiocardiograms that we carried out in 60 cases of Fallot's tetralogy. In addition to the usual findings which are now well recognized (Steinberg and Dotter, 1951; Lowe, 1953; and Hilario et al., 1954), we have been able to add certain observations on the aorta and its branches and also on the right and left pulmonary arteries (R.P.A. and L.P.A.) which we record here.

In all cases, angiocardiograms were taken in the antero-posterior (A.P.) position. In some instances the right anterior oblique position (R.A.O.) was used when a second examination was required to demonstrate the site of the stenosis. We found the left anterior oblique position (L.A.O.) to be the optimum view in assessing the degree of aortic override. All examinations were performed with the patient supine on a single plane film changer providing films at approximately $0 \cdot 8$ second intervals at an anode-film distance of 48 inches.

\section{The Aorta in Fallot's Tetralogy}

The overriding aorta is of course one of the diagnostic features of the tetralogy. On angiocardiography this is shown by early opacification, as the aorta fills simultaneously with the pulmonary trunk from the right ventricle.

In Fallot's tetralogy the ascending aorta is always enlarged particularly in adults. A good example of this is shown in Fig. 1 from a woman, aged 52, who had been under observation for 20 years (Bedford, 1929 and 1956). In cases of pulmonary atresia a giant aorta may be seen (pseudo truncus arteriosus), the so-called truncus aorticus of French authors. Brinton and Campbell (1953) found the diameter of the aorta averaged $17.1 \mathrm{~mm}$. compared with $10.4 \mathrm{~mm}$. for the pulmonary trunk in 25 specimens at necropsy, whereas the two vessels are approximately equal in diameter in the normal.

On the plain X-ray the aortic knuckle is always visible in Fallot's tetralogy unless obscured by a left superior vena cava. The large comma-shaped ascending aorta usually imparts an increased convexity to that part of the right pedicular contour, formed by the superior vena cava. This is in contrast to pulmonary valvular stenosis with a normal aortic root, where the aortic knuckle is often insignificant and obscured by a large left pulmonary artery and that part of the right pedicular contour formed by the superior vena cava and adjacent aorta is straight (Bedford, 1955).

The abnormal size and shape of the aorta and aortic arch in Fallot's tetralogy can be best studied from angiocardiograms. In the A.P. position the ascending aorta is large and forms an unusually prominent arc to the right as already described and in many cases, owing to the dextroposition of the aortic root and the shape of the ascending aorta, the ascending and descending

\footnotetext{
* Duchess of Bedford Research Fellow.
} 


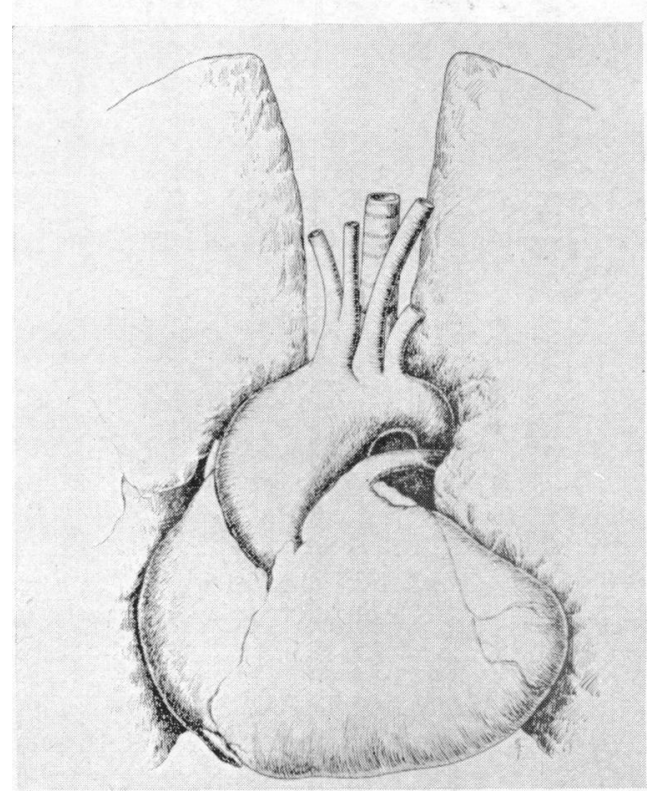

Fig. 1.-Fallot's tetralogy. Woman, aged 52 years. Specimen drawn in situ, showing unusually large ascending aorta narrowing abruptly at the isthmus.

limbs of the arch are more widely separated (Fig. 2A and C). These observations apply only to cases with a left-sided aortic arch. The widening of the aortic arch and increased curvature of the ascending limb can be seen best in the L.A.O. position (Fig. 2B and D). Another characteristic feature of the aortic arch in Fallot's tetralogy is the sudden narrowing of the vessel that occurs immediately distal to the origin of the left subclavian artery. We found one exception to this where the aortic arch suddenly narrowed $5 \mathrm{~cm}$. distal to the origin of the left subclavian artery.

In order to demonstrate these points we measured the width of the aortic shadow when filled with contrast medium at the upper level of the twelfth dorsal vertebra, at the arch just distal to the origin of the left subclavian artery and $2 \mathrm{~cm}$. above the valves. The ratio of these measurements were compared. The actual aortic sizes could not be used owing to the wide range of ages and differing body builds in a relatively small number of observations. These findings were compared with similar measurements obtained from a small series of cases in which angiocardiograms had been done for pulmonary lesions, the heart and aorta being normal. In normal cases the ratio of the aortic diameters at the three sites mentioned above (descending aorta, arch of aorta, and root of aorta) was $1: 1 \cdot 3: 1 \cdot 7$ compared with $1: 1 \cdot 7: 2 \cdot 4$ in Fallot's tetralogy.

The degree of aortic override in Fallot's tetralogy is difficult to assess from angiocardiograms. A fair estimate can be made, however, from the relation of the aortic root to the interventricular septum, which is best demonstrated in the L.A.O. position. It appears that the more anterior the aortic root in this view, the greater the degree of override. We could find little if any correlation between the diameter of the ascending aorta and the amount of override either in our cases or from a study of the necropsy figures published by Donzelot et al. (1952). This may be due to the varying calibre of the aorta with age.

A separate series of 13 necropsy specimens from cases of Fallot's tetralogy have also been examined and the observations concerning the size and shape of the aorta were confirmed. Unfortunately only one of these cases was studied angiocardiographically before death.

There was a right-sided aortic arch in 12 cases $(20 \%)$ of our series. In all these patients the 

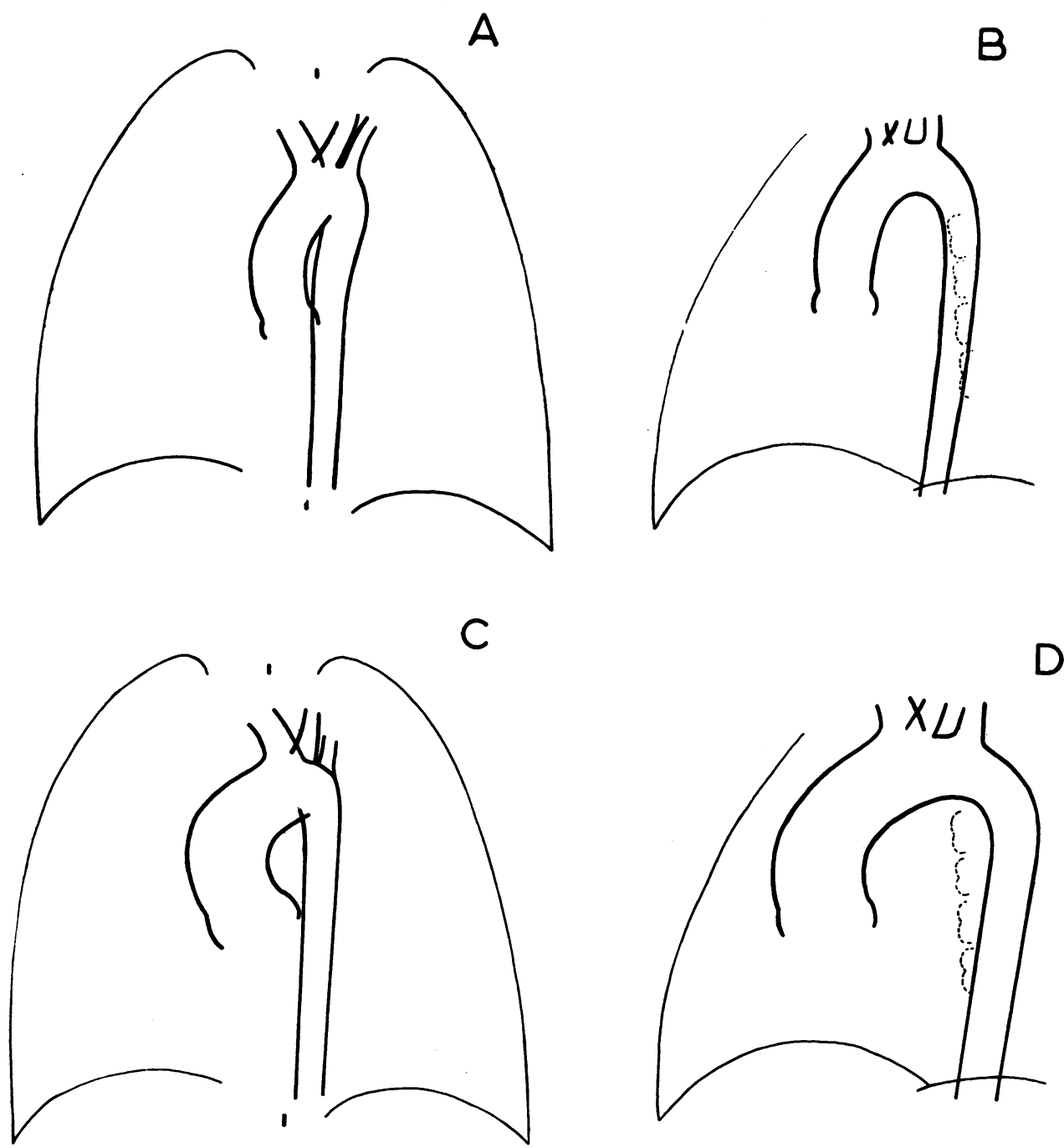

FIG. 2.-Diagrams of the normal aorta and the aorta in Fallot's tetralogy. (A) Normal aorta (A.P.). (B) Normal aorta (L.A.O.). (C) Aorta in Fallot's tetralogy (A.P.). (D) Aorta in Fallot's tetralogy (L.A.O.).

upper part of the descending aorta lay on the right side and crossed to the left of the midline in the lower third of the thorax. In such cases the right-sided aortic arch and its branches commonly form a mirror image of the normal, the first branch of the arch being a left innominate artery. In one of our cases, however, the left common carotid artery was the first branch while the left subclavian artery originated as the fourth and last branch from the arch and ran a retro-œsophageal course.

We obtained good visualization of the aortic branches in 43 out of 48 cases with a left-sided aortic arch. An anomalous retro-œsophageal right subclavian artery was present in $6(14 \%)$. Four of these have been previously described in greater detail by one of us (Pattinson, 1953). This incidence is much higher than that in the general population quoted at 0.6 per cent (Holzapfel, 1899) to 0.8 per cent (Cairney, 1925). In our experience there is no unusual frequency of an anomalous right subclavian artery in other forms of congenital heart disease. 

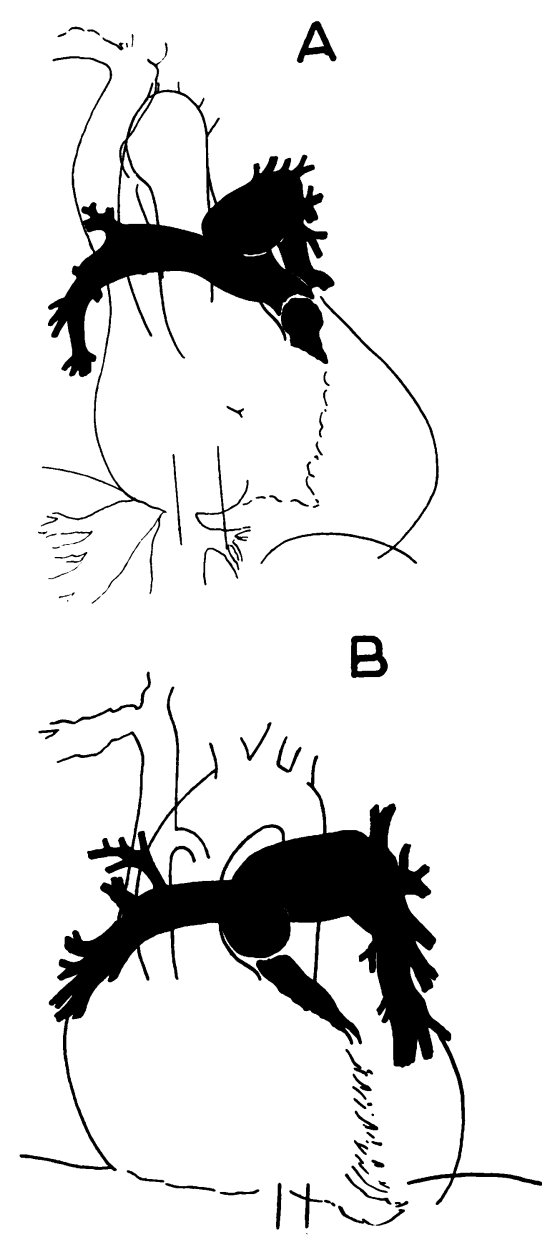
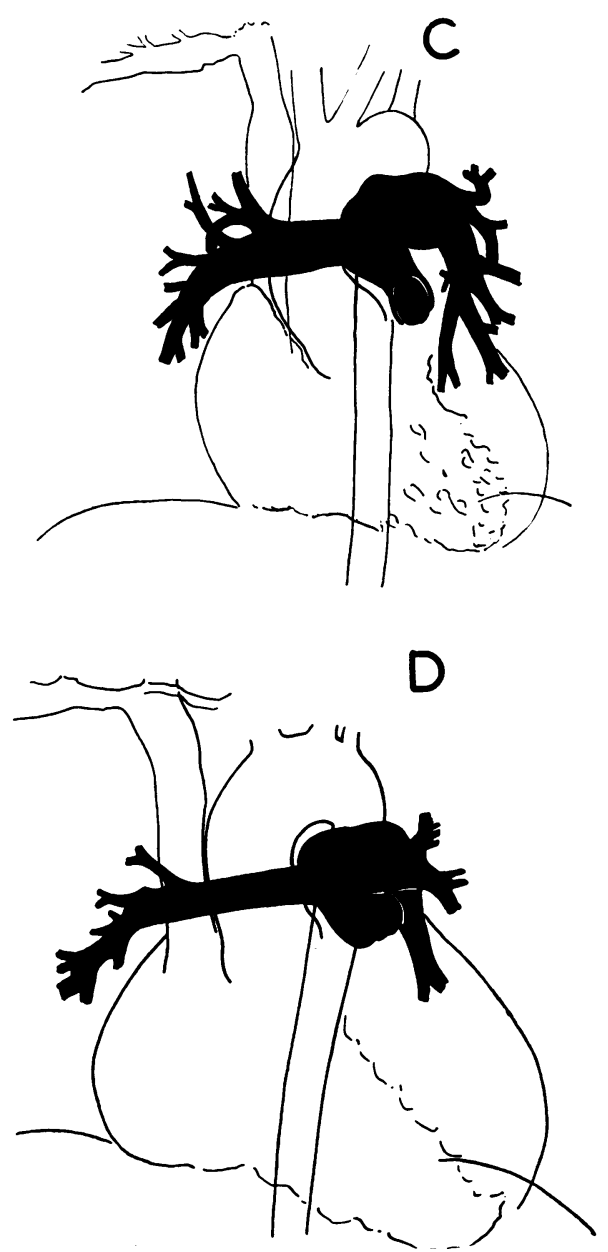

FIG. 3.-Tracings from angiocardiograms in four cases of Fallot's tetralogy in which the left pulmonary artery is larger than the right. (A) Woman, aged 50 years. (B) Boy, aged 6 years. (C) Boy, aged 5 years. (D) Girl, aged 9 years.

The Pulmonary Arteries in Fallot's Tetralogy

The site of the pulmonary stenosis in Fallot's tetralogy can be determined in the majority of cases, particularly if angiocardiograms are taken in two views (A.P. and R.A.O.). If, however, the films are taken at intervals of $0.8-1.0 \mathrm{sec}$., great care must be taken in diagnosing abnormalities of the infundibulum as the shape of this muscular chamber varies greatly with the various phases of the cardiac cycle.

The pulmonary trunk is frequently small in Fallot's tetralogy partly accounting for the concave or straight pulmonary artery segment seen in the plain X-ray. In one-third of our cases we found considerable difference in the diameter of the two pulmonary arteries, when measured $1 \mathrm{~cm}$. from the bifurcation of the pulmonary trunk. This difference amounted to $0.5 \mathrm{~cm}$. or more in 19 out of 60 cases and in 17 instances it was the left that was larger than the right. Fig. 3 shows four typical examples. This was an unexpected finding as in the normal the right is a little larger than the left (Schafer and Thane, 1899; Brash, 1951; and Johnston and Whillis, 1947). There is probably an embryological explanation for this finding and therein may lie further support for Bremer's 
view, that the adult right and left pulmonary arteries arise from different embryological structures (Bremer, 1909; Emanuel and Pattinson, 1956).

The site of the stenosis was visualized in 15 of the 19 cases where there was unequal division of the pulmonary trunk. Both the pulmonary valve and infundibulum were abnormal in 13 cases, while in the remaining 2 the infundibulum alone appeared stenosed. Where the size of the R.P.A. and L.P.A. were equal the site of the stenosis was visualized in 33 of the 41 cases. The pulmonary valve and infundibulum were abnormal in 14, the valve alone was involved in 2 cases, while in the remaining 17 , the stenosis appeared to be confined to the infundibulum. Thus pulmonary valvular stenosis was more frequent in the cases where there was unequal division of the pulmonary trunk. It must be remembered, however, that with the technique used an infundibular stenosis may mask a co-existent pulmonary valvular stenosis.

In only one case where there was unequal division of the pulmonary trunk did we have the opportunity of confirming our observations at necropsy; this was in a male, aged 19, where the L.P.A. was larger than the R.P.A.

The unequal size of the pulmonary arteries was never sufficient to cause any difference in opacification of the periphery of the lung fields.

A rare anomaly in Fallot's tetralogy is the absence of the left pulmonary artery. We have recorded 2 cases and reviewed a further 18 (Emanuel and Pattinson, 1956).

\section{SUMMARY}

In Fallot's tetralogy the ascending aorta is enlarged. It narrows rapidly at a point immediately distal to the origin of the left subclavian artery. Owing to the dextroposition of the aortic root and shape of the ascending aorta the ascending and descending limbs of the arch are more widely separated than in the normal.

In all our cases associated with a right-sided aortic arch the descending aorta crossed to the left of the midline in the lower third of the thorax.

In Fallot's tetralogy an anomalous retro-œsophageal right subclavian artery occurred in 14 per cent of cases, compared with a frequency of about 0.7 per cent in the population as a whole.

In a third of our cases of Fallot's tetralogy there was unequal division of the pulmonary trunk (19 out of 60 cases) and in the majority (17 instances) the left pulmonary artery was the larger branch. Unequal size of the pulmonary arteries did not appear to affect the lung filling.

We wish to thank Doctors Evan Bedford and Walter Somerville for their help with this paper.

\section{REFERENCES}

Bedford, D. E. (1929). Proc. Roy. Soc. Med., 23, 130.

(1955). Personal Communication and Communication to the San Francisco Heart Association.

(1956). Proc. Roy. Soc. Med., 49, 314.

Brash, J. C. (1951). Cunningham's Text Book of Anatomy. 9th ed. p. 1242, Oxford University Press, London.

Bremer, J. L. (1909). Anat. Rec., 3, 334.

Brinton, W. D., and Campbell, M. (1953). Brit. Heart J., 15, 335.

Cairney, J. (1925). J. Anat. Lond., 59, 265.

Donzelot, E., d'Allaines, F., Dubost, Ch., Metianu, G., Durand, M., and Dubost, C. (1952). Sem. Hôp., $28,877$.

Dotter, C. T., and Steinberg, I. (1951). Angiocardiography, Annals of Roentgenology, Vol. 20. Paul B. Hoeber, Inc., New York.

Emanuel, R. W., and Pattinson, J. N. (1956). Brit. Heart J., 18, 289.

Hilario, J., Lind, J., and Wegelius, C. (1954). Brit. Heart J., 16, 109.

Holzapfel, G. (1899). Anat. Hefte, Beitrage, 12, 373.

Johnston, T. B., and Whillis, J. (1947). Gray's Anatomy. 29th ed., p. 173, Longmans Green and Co., London.

Lowe, J. B. (1953). Brit. Heart J., 15, 319.

Pattinson, J. N. (1953). Brit. Heart J., 15, 150.

Schafer, E. A., and Thane, G. D. (1899). Quain's Elements of Anatomy. Vol. 2, Part 2, p. $378 . \quad$ Longmans Green and Co., London. 